\title{
Benign Mixed Epithelial and Mesenchymal Hair Follicle Neoplasm
}

National Cancer Institute

\section{Source}

National Cancer Institute. Benign Mixed Epithelial and Mesenchymal Hair Follicle

Neoplasm. NCI Thesaurus. Code C43322.

A benign mixed epithelial and mesenchymal type neoplasm occurring in the hair follicle. 